Commentary on Targeting Catholic Rituals as Symptoms of Obsessive Compulsive Disorder: A Cognitive-Behavioral and Psychodynamic, Assimilative Integrationist Approach

\title{
Treatment Paradigms in Psychology
}

\author{
JAMES MANDALA ${ }^{\text {a,b }}$ \\ ${ }^{\text {a }}$ Rutgers - The State University of New Jersey \\ ${ }^{b}$ Correspondence concerning this article should be addressed to: James Mandala, Rutgers University Health \\ Services, Assistant Director of Counseling And Psychological Services, 247 Tillett Hall, Livingston Campus, \\ Piscataway, NJ 08854 \\ Email: mandala@rci.rutgers.edu
}

\begin{abstract}
This commentary describes my observations as the clinical supervisor of Dr. Hector Garcia's (2008) second, psychodynamic phase of therapy with "Bridget," which followed a first phase of successful cognitive-behavioral treatment for specific, obsessive-compulsive symptoms with religious content. The second treatment phase focused on less structured issues such as, in Dr. Garcia's words, "the qualities and patterns of past relationships with men, her current social network, and dynamics within her family of origin.” This case raises a number of complex and highly important, general issues. The ones I have chosen to discuss are: (a) the meaning of "compulsive" versus "healthy” prayer; (b) the sequencing of the theoretical shift from cognitivebehavioral to psychodynamic therapy; (c) the utilization of countertransference phenomena and the "real" relationship in psychotherapy; and (d) the impact of eclecticism in the training of beginning therapists.
\end{abstract}

Key words: psychodynamic therapy; cognitive-behavioral therapy; compulsive praying; countertransference; eclecticism; therapy training

The shape of the food depends upon how you slice the bologna. -- Nathan Adler, Ph.D., 1984

When I was in graduate school I lived in Santa Cruz, California, near the shore of Monterey Bay, where I had the good fortune of knowing several biologists who studied marine life. One scientist was researching the unique physiology of the California torpedo fish (the Pacific electric ray), which can stun prey using discharges from its electric organ. The torpedo fish can weigh close to 90 pounds and grow to lengths of more than four and a half feet.

Specimens were collected in large nets used by commercial fisherman. These nets are hundreds of feet long and had meshes with openings that are several inches wide to prevent them from being clogged by smaller fish. Another biologist I knew was investigating microscopic plankton populations in Monterey Bay. She collected her specimens with a plankton net, which was comprised of a small metal ring, a few inches across, to which was attached a three-foot nylon 
stocking. A naïve observer could drag the plankton net through the water and report a bay full of plankton, without any torpedo fish. Likewise, on the same day, someone could drag the commercial fishermen's net all the way across bay and report the bay had plenty of torpedo fish in it, but no plankton.

I believe psychological theories, and their corresponding therapeutic systems, are very much theoretical "nets." They allow one to capture and study certain phenomena; but, because of their specificity, they miss, or render invisible, other phenomena. The case of Bridget is especially interesting because the clinician, Hector Garcia (in press), "switched nets" in the middle of the treatment - something often done by experienced, pragmatic therapists who define themselves as “eclectic.” These theoretical shifts, however, are rarely done as deliberately and thoughtfully as they were in this case.

While Hector Garcia was a graduate trainee, I served as his clinical supervisor during the second part of Bridget's treatment (Garcia, 2008). (Note that Dr. Garcia originally wrote up the case while a student, but did the final conceptualization and writing after he graduated with his doctorate in clinical psychology.) I found his work to be a wonderful illustration of how techniques taken from different therapeutic approaches can be integrated sequentially. Combined, these approaches provide a treatment for the client that is superior to a treatment utilizing either approach alone. He clearly shows how radically different interventions can be combined by the same therapist when working with a client -- even when the theories underlying the therapeutic techniques are generally thought of as mutually exclusive.

With the above as conceptual context, I would like to remark upon this case by focusing upon the following issues:

- Dr. Garcia's decision to work with Bridget to treat her obsessive praying, which I did not supervise.

- The sequencing of the theoretical shift from cognitive-behavioral to psychodynamic.

- Utilization of countertransference phenomena and the "real” relationship in psychotherapy.

- The impact of eclecticism in the training of beginning therapists.

\section{THE MEANING OF PRAYER}

Our conscious motivations, ideas, and beliefs are a blend of false information, biases, irrational passions, rationalizations, prejudices, in which morsels of truth swim around and give the reassurance albeit false, that the whole mixture is real and true. The thinking processes attempt to organize this whole cesspool of illusions according to the laws of plausibility. This level of consciousness is supposed to reflect reality; it is the map we use for organizing our life.

- - Erich Fromm, To Have or to Be?, 1979 
A careful exploration of the therapist's life-world, as it related to the client's experiences, was generally useful in this case. In his case study, Dr. Garcia (2008) carefully explained how his attention to clinical phenomenology allowed him to distinguish compulsive praying from healthy prayer. He worked very respectfully with Bridget, helping her determine what was a symptom and what was a genuine manifestation of her religious beliefs. This allowed the two of them to attack the compulsive praying without eroding Bridget’s religious practices.

One could have looked at Bridget's compulsive praying from a more developmental framework. James Fowler's (1995) exploration of religious faith from a developmental perspective would place Bridget's compulsive praying within the realm he describes as mythicliteral faith. This is the faith of a school child, characterized by the child taking on the myths, observances and beliefs of his community in a concrete way. Fowler lists this type of faith as the second stage in a developmental sequence of five stages that roughly parallels Piaget's (1955) cognitive stages or Kohlberg's (Kohlberg, Levine, \& Hewer, 1983) moral stages. It was clear from Bridget's explanations of her religious beliefs that these beliefs - independent of her religious rituals -- were more advanced developmentally than the mythic-literal practices that the compulsive praying would suggest. Her religious and moral perspective was more sophisticated and evolved. It was more adult than childlike. The disparity between Bridget's level of spiritual development and the level of spiritual development associated with her compulsive praying would also justify targeting her praying rituals therapeutically.

Upon reflection, it also seems clear that Dr. Garcia was able to clearly appreciate the neurotic nature of the obsessive praying because of his own worldview. Dr. Garcia's personal approach to life tends to be somewhat reflective and philosophical. It is likely that from that philosophical stance, he would have a felt sense of how trapped Bridget was with this compulsion to pray, and how inauthentic compulsive prayer would be as a spiritual gesture. Like Bridget, Dr. Garcia's spiritual development had proceeded well beyond the more primitive mythic-literal stage. He was able to intuitively grasp the dissonance between Bridget's beliefs and neurotic practices because he himself had long ago left behind the mythic-literal stage of spiritual development.

This felt sense was also useful in the second phase of the therapy when Bridget was working through some of her values related to sexuality. Dr. Garcia was careful not to impose external values upon Bridget. Instead, he used a non-judgmental stance to help her. This nonjudgmental stance flowed from what I believe was one of the keys to success with Bridget: Dr. Garcia's genuine feelings of care, respect, and appreciation for her.

\section{TREATMENT SEQUENCE}

First things first, but not necessarily in that order.

-- Dr. Who (Flanagan \& McCullough, 1980)

Many psychoanalytic, humanistic, existential, and interpersonal psychologies are predicated on the reparative qualities of the relationship between the therapist and the client. This relationship is often characterized by a number of features: 
- The therapist remains a tabula rasa to the client, revealing little of his or her personal life in order to keep the focus on the client's lived world as well to provide a screen for transferential projections onto the therapist that can be worked through in treatment.

- The clinician initially approaches the client's difficulties with therapeutic neutrality, not judging the client's behavior, conscious goals, or unconscious impulses. (

- The clinician initially responds to the client using reflection, amplification, and only eventually with interpretation and confrontation.

The general motion during most dynamic treatments is from being less active to becoming more active during the treatment. This brings to mind the old joke about psychoanalysis:

When the beginning analysand complained that his analyst said almost nothing to him even though he was paying lots money for treatment, the analyst replied, “Don't worry. Just wait a few months and you'll be willing to pay me twice as much to say nothing instead of interpreting the things you say!”

The shift between cognitive-behavioral and psychodynamic/interpersonal approaches to treatment seems to reverse the natural flow of communications in psychodynamic treatments. Many therapists who are trained analytically or interpersonally report almost following a clientcentered approach during early sessions, giving the client little direction. Only later, when they have a deeper understanding of the client's world, do they become more active or more directive. For many, any deviation from therapeutic neutrality, from "evenly-suspended attention,” would be damaging to the relationship. The therapist is expected to avoid focusing on any particular part of the client's communication to avoid interfering with the client's unfolding of their narrative.

The first, cognitive-behavioral phase of Dr. Garcia’s treatment with Bridget involved targeting symptoms aggressively and directly. The therapist was not a tabula rasa, but was instead an active agent, working with the client in the service of mental health. This makes perfect sense, given Bridget's impairment by her obsessive symptoms. One would expect the sequence of treatment approaches in this case, moving from the cognitive-behavioral to the psychodynamic, to be problematic. It is easy to imagine that the aggressively active cognitivebehavioral treatments would strongly contaminate any, later attempt at psychodynamic work. Nevertheless, Dr. Garcia reports, "The transition from CBT to less structure went smoothly and Bridget soon found a rhythm for talking without a palpable format.” He noted that he needed to cue her initially with "example topics for exploration.” These included "qualities and patterns of past relationships with men, her current social network, and dynamics within her family of origin.” This cueing was probably necessary because the first phase of the treatment was strongly dependent upon Dr. Garcia providing structure and focus to the sessions. His "example topics” were actually open-ended directives. This need to cue Bridget's talk did not persist, and Dr. Garcia’s future directives tended to be therapeutic responses to the material she presented. 
I believe that this transformation proceeded as smoothly as it did because of Bridget's temperament and personality, and because of the nature of the previous relationship between her and Dr. Garcia. I refer here not to the careful and methodical work that was done treating the obsessions, but rather to the relationship between Dr. Garcia and Bridget. Their relationship was characterized by what Young et al. (2003) would call a "true emotional bond.” It may be that the authentic presence and caring of Dr. Garcia, which nurtured the relationship during the cognitive-behavior treatment, actually laid a deep foundation for the psychodynamic work done in the second year of treatment.

\title{
EVOLVING TREATMENT FOCUS
}

\author{
The only thing that makes life possible is permanent, intolerable uncertainty: \\ not knowing what comes next. \\ -- Ursula LeGuin (1969)
}

I believe one of the factors that made a psychodynamic approach especially fruitful for the second phase of Bridget's treatment consisted of the way she approached therapy during this phase. Unlike the first phase of treatment, Bridget did not articulate a set of specific symptoms that could be easily defined and targeted as concrete or specific goals for treatment. Her desire to have a meaningful and successful romantic relationship is not especially unusual or neurotic; nor is the lack of success with men unusual for a woman of this client's age. In many ways the heart of her problem was hidden. As Dr. Garcia noted, Bridget denied the importance of her father's death, and the impact this had on her relationships.

In approaching this case psychodynamically, the focus of treatment was able to evolve organically over time as Dr. Garcia and Bridget worked together. Bridget's resistance to working with the material triggered by her father's death was so strong in the beginning of this treatment phase that a more directive approach would not have been helpful. She would not have agreed to explore the patterns that were triggered by the loss of her relationship with him because it was too painful. A more cognitive-behavioral treatment would have required a clear treatment focus. Even a strategic treatment would have required a concrete definition of a problem in the beginning (Watzlawick, 1974).

Psychodynamic interpretations have numerous functions, but they may be generally understood as attempts to break through the universal defense of self-deception. (Fingarette, 2000) Ultimately the self-deception must be challenged by the client herself, integrating both affect and intellect. Premature interpretations by the therapist may be disruptive of the therapeutic bond, if they tread upon sensitive material and are experienced by the client as empathic failures. At other times the client may simply ignore them. In this case, the solid therapeutic collaboration between Dr. Garcia and Bridget ultimately enabled her to explore this material. In my view, this was only possible after the second part of the therapy had continued long enough for the relationship between the two of them to develop more fully. Bridget denied the relevance of the traumatic loss of her father in her current emotional life and in her romantic relationships. As treatment progressed, it appeared that this denial was actually a self-deception. 
One frequent supervisory focus in Dr. Garcia’s treatment of Bridget was an examination of how interpersonal perceptions were distorted by both transference and countertransference phenomena. Dr. Garcia and I were able to examine both these reactions in detail during our weekly supervision sessions. During supervision, Dr. Garcia elucidated the positive paternal transference that the client seemed to experience toward him. This transferentially charged relationship is likely to have served a critical function. By replicating the positive "emotional holding” environment (Winnicott, 1960) that Bridget experienced with her father, it stirred up some of the feelings that Bridget needed to work through before she could have successful relationships with men. Additionally, the "real” relationship with Dr. Garcia was also critical to this moving forward. The safety of the holding environment meant that Dr. Garcia's caring presence would allow Bridget to bravely open up those old wounds and explore them. She could challenge the self-deception, and unpack its implications in the romantic relationships she became caught up in.

The therapy eventually began to be driven by the affective charge of present events in the client's life, most notably her breakup with her out-of-state boyfriend after his infidelity. This obviously triggered feelings of loss for the client. I believe, however, that the relationship with Dr. Garciā may have served as a buffer for Bridget, supporting her with an intimate emotional connection, even though it was bounded by the therapeutic frame.

\section{ECLECTICISM IN TRAINING}

One of the advantages of being disorderly is that one is constantly making exciting discoveries. - - A.A. Milne, English juvenile author (1882 - 1956)

(quoted in from Fitzhenry, 1987)

Like many therapists in modern doctoral programs, Hector Garcia was trained broadly in a fairly wide variety of theoretical approaches and therapeutic disciplines. This eclecticism is what allowed him to change focus in the middle of his treatment. Although much of his early training was in cognitive-behavioral work, at the time I began supervising him he was studying psychoanalytic diagnosis and treatment (e.g., McWilliams, 1999, 2004) as part of his graduate studies. It is likely that this fueled his interest in shifting to a less directive and more psychodynamic exploration of his client's world.

Dr. Garcia elucidates various ways in which theoretical approaches are combined by therapists. He identifies his position most closely with Messer's (1992) description of "assimilative integration," in which the therapist maintains a theoretical stance, but utilizes techniques or perspectives from other areas. Most of the trainees and interns I have supervised in the past several years have taken an assortment of classes that expose them to cognitivebehavioral, psychodynamic, family systems, and community psychology approaches to client interventions. Some have also been occasionally trained with various existential, humanistic, transpersonal, and communication approaches to therapy. This scattered exposure to different modalities pushes them in the direction of many experienced therapists, who become more flexible in the techniques they use, independent of their theoretical bent. However, the training of beginning therapists with such an eclectic mix of approaches creates two specific problems: 
1. The trainee is uncertain which set of techniques would be most helpful to a specific client.

2. It becomes difficult to explore the use of the therapist's self or countertransferential distortions of treatment.

Supervision can be difficult when a therapist in training does not focus on a particular theoretical approach and sticks with it. In the early years of practice, the therapist needs to learn how to use his or her self as an instrument in the healing of others. A new therapist needs to understand what neurotic schema triggered the novice to choose to become a therapist in the first place. As Richard Knowles (1986) once pointed out, "People without neuroses would be bored listening to other people's problems all day." The therapist career choice can be motivated by a myriad of overlapping drives: a need to rescue, to feel omnipotent, to engage intensely without becoming vulnerable, to heal one's self by proxy, to compulsively relive one's own traumas, and so forth. The therapist's neurotic needs can serve as a source for distortions in the perception of the client's needs, but also as a source for accurate empathy towards the client's struggles and pain. In addition, many would argue that distortions and failures in empathy are actually an inevitable part of any good therapy, and if utilized well, may actually become the key element in the reparative mechanism of the therapy.

Beginning therapists almost always fixate on issues of technique, "What is the correct thing to say?” For example, anxious clinicians continuously question and doubt which technique they used; while narcissistic clinicians want to show the supervisor and client how brilliant and powerful they are so they can be admired. As Irving Yalom (1980) noted, the healing component of therapy may actually transcend technique.

In the early years of training, clinicians need to learn disciplined strategies for helping their clients based upon therapeutic principles, rather than their own neurotic projects. When a client and therapist enter together into a therapeutic relationship, a kind of interpersonal field is set up. The therapeutic discipline, with specific strategies and techniques, often feels confining to the beginning therapist. There are strong pulls to deviate away from the cognitive behaviorist's treatment protocol, the analyst's neutrality, or the humanist's unconditional positive regard. The supervisor and clinician should deconstruct these pulls together.

When beginning therapists define themselves as "eclectic," they often "mix and match" intervention techniques from different theoretical frameworks without theoretical cohesion. This may be somewhat effective, just as a shotgun with a wide shot-pattern is bound to hit something. This approach may make sense from a naïve scientific perspective. If something doesn't work, it makes sense to try something else. When we think of humans as strongly motivated by unconscious forces, however, the eclectic approach becomes dangerous for beginning therapists. The unconscious pulls to respond directly to the client's problems then easily go unchallenged. "Eclecticism" as a therapeutic orientation can generally justify any intervention, even if it is driven by the therapist's unconscious needs rather than the client's therapeutic needs.

I believe that it is the collision between the therapist's impulses and a strong theoretical discipline that teaches beginning therapists how to use themselves in the therapeutic process. 
Since eclectic therapists can often find justifications for most interventions, there is no theoretical map to guide the trainee. It becomes much more difficult to uncover the unconscious projects that the trainee may be engaged in. These projects may be triggered by material presented by the client, patterns inherent in the trainee's patterned behaviors or character, or reactions to life events outside of the therapeutic relationship. The supervisor must be extremely vigilant if the supervisee is to maximize learning while using such an atheoretical approach.

It is critical that clinicians learn to separate their clients' conflicts from their own. As Roy Schafer (1999) pointed out, clinicians need to appreciate the client's resistance, rather than dismiss it. Dr. Garcia started his professional training with a strong cognitive-behavioral orientation. His work with Bridget was an early foray into the broader, psychodynamic world. During this foray, he maintained a strong cognitive-behavioral anchor that led him to favor more active interpretations and interventions. This can also be understood, however, in the context of the relational "pull” of the client, as Bridget worked through many of the issues that were unresolved after her father's death. If one conceptualizes where she was stuck developmentally, i.e., in the movement from latency into adolescence, then the more activist, collaborative approach of Dr. Garcia is a nice fit with the developmental needs of someone working through those early issues of intimacy and connection. Like the parent of a teenager, who communicates respect and support but provides a lot of guidance, there is strong clinical evidence that Dr. Garcia provided corrective emotional experiences for Bridget.

\section{FINAL REMARKS}

The idea is to try to give all the information to help others to judge the value of your contribution; not just the information that leads to judgment in one particular direction or another. - Richard Feynman, Physicist (1985)

I would like to conclude by noting how it took a certain amount of intellectual courage for Dr. Garcia to move away from his cognitive-behavioral orientation during the treatment. He was able to explore material non-defensively and with a good sense of his own internal processes. It is possible that the supervision process may have trickled down to Bridget through a parallel process - that is, Dr. Garcia's courage in exploring a new way of looking at therapy may have unconsciously encouraged Bridget to courageously explore her own lived experiences.

In closing, I would like to extend my appreciation to the PCSP journal's policy of publishing cases like Dr. Garcia's in organized, systematic, and rich detail since it allows each of us -- both commentators and readers -- to drag our different theoretical nets through the particular sea of descriptive material presented by such cases.

\section{REFERENCES}

Adler, N. (1984). Lecture at California School of Professional Psychology, Berkeley, CA. Flanagan, J., \& McCulloch, A. (1980, Fall season). Dr. Who, BBC Television Series. Feynman, R. (1985). Surely you're joking, Mr. Feynman. New York: W.W. Norton. 
Fingarette, Herbert. Self-deception. Berkeley: University of California Press, 2000.

Fitzhenry, R. (1987). Barnes and Noble book of quotations. New York: Harper and Row.

Fowler, J. (1995). Stages of faith: The psychology of human development. San Francisco: Harperone.

Fromm, E. (1976; reprinted, 2005). To have or to be? New York: Continuum International Publishing Group.

Garcia, H.A. (2008). Targeting Catholic rituals as symptoms of obsessive compulsive disorder: A cognitive-behavioral and psychodynamic, assimilative integrationist approach. Pragmatic Case Studies in Psychotherapy [Online], Vol. 4(2), Article 1, 1-38. Available: http://hdl.rutgers.edu/1782.1/pcsp_journal

Kohlberg, L., Levine, C., \& Hewer, A. (1983). Moral stages : A current formulation and a response to critics. Basel, NY: Karger.

Knowles, R.T. (1986). Human development and human possibility: Erikson in the light of Heidegger. New York: University Press of America.

LeGuin, U. (1969). The left hand of darkness. New York: The Berkeley Publishing Group. McWilliams, N. (1999). Psychoanalytic case formulation. New York: The Guilford Press.

McWilliams, N. (2004). Psychoanalytic psychotherapy: A practitioner's guide. NewYork: Guilford.

Messer, S. B. (1992). A critical examination of belief structures in integrative and eclectic psychotherapy. In: J.C. Norcross \& M.R. Goldfried (Eds.), Handbook of psychotherapy integration, 130-165. Basic Books: New York.

Piaget, J. (1955). The child's construction of reality. London: Routledge and Kegan Paul.

Schafer, R. (1999) The analytic attitude. New York: Basic Books.

Watzlawick, P. (1974). Change: Principles of problem formation and problem resolution. New York: W. W. Norton \& Company.

Winnicott, D. (1960). The theory of the parent-child relationship, Int. J. Psychoanal., 41, 585595.

Yalom, I.D. (1980). Existential psychotherapy. New York: Basic Books, 1980.

Young, J.E., Klosko, J.S., \& Weishaar, M.E. (2003). Schema therapy: A practitioner's guide. New York: Guilford. 